Glukhova N. V., PhD

\title{
EXPERIMENTAL RESEARCH METHODS OF METROLOGICAL CHARACTERISTICS OF REGISTRATION CHANNELS IMAGES
}

The problems of creating of metrological support in the registration of measurement information in the form visual data were reviewed. Analysis of the sources of uncertainty in the registration, processing and analysis of analogue and digital gas-discharge light images was performed. The calibration methods of measuring channels intended for registration, conversion and transmission of image data have been proposed. The developed methods and calibration schemes enable experimental evaluation of the metrological characteristics of the image data acquisition channels.

Keywords: metrological support, measurement information, the uncertainty of measurement, calibration, gas-discharge light.

УДК 621.317

А. Н. Василевский ${ }^{1,2}$, д.т.н., О. Д. Никитенко ${ }^{2}$, к.т.н.

${ }^{1}$ Министерство образования и науки Украины, г. Киев

${ }^{2}$ Винниикий национальный технический университет, г. Винница

\section{ИССЛЕДОВАНИЕ НЕОПРЕДЕЛЕННОСТИ ИЗМЕРЕНИЯ КОНЦЕНТРАЦИИ ИОНОВ ПРИ ИСПОЛЬЗОВАНИИ СРЕДСТВА ИЗМЕРЕНИЯ ПОСТРОЕННОГО ЗА ПРИНЦИПОМ АНАЛОГО-ЦИФРОВОГО ПРЕОБРАЗОВАНИЯ}

Выполнено оченивание точности измерения концентрачии ионов с учетом международных требований к подачи качества результатов измерений. Установлено значение суммарной неопределенности типа B, которое обусловлено ограниченными свойствами составляющих элементов средства измерения концентрачии ионов.

Ключевые слова: уравнение преобразования, концентрачия ионов, стандартная неопределенность, средство измерения, ионоселективный преобразователь.

\section{Введение.}

Задача оценивания точности измерений с учетом международных требований к подачи качества результатов измерений является актуальной в связи с курсом Украины на Евроинтеграцию. Для сравнения результатов измерений, полученных в Украине с результатами, которые имеют ведущие европейские лаборатории необходимо иметь соответствующую методику оценивания неопределенности конкретного вида измерений, которая позволит осуществлять такое сравнение.

Автоматизация процесса измерения концентрации ионов гумусового состояния почв была и является важной задачей сельского хозяйства. Она открывает широкие возможности повышения качества урожайности многих видов сельскохозяйственных культур, но для этого нужно иметь средства измерения, которые позволят точно определять концентрацию ионов гумусового состояния почв с соответствующим метрологическим обеспечением, которое позволит выполнять оценивание качества измерений и пода- вать результаты измерений с учетом концепции неопределенности.

Анализ последних исследований и публикаций. Современные методы аналитической химии гумуса позволили установить основные соединения, функциональные группы и элементы, которые входят в химический состав таких частей гумуса, как гумусовые кислоты и негидролизированный остаток $[1,2]$.

Опыт химического анализа гумусовых веществ дает возможность определить основные признаки, которые имеют вещества, относящиеся к гумусовым [3]. Для гуминовых кислот массовая доля углерода находится в пределах 46$62 \%$, для фульвокислот - $36-44 \%$. Одновременно содержание азота в фульвокислотах находится в пределах $3-6 \%$. Важнейшими азотосодержащими веществами, что оказываются в почвах в свободном состоянии и могут рассматриваться как предшественники гумусовых кислот есть: белки, полипептиды, аминокислоты, нуклеиновые кислоты и хлорофилл. 
Использование ферментного гидролиза показывает, что значительная часть азота, представлена аммонийными формами, среднее содержание групп $\mathrm{NH}_{4}$ составляет в гуминовых кислотах дерново-подзолистых почв 1,38 \%, черноземов $-0,75 \%$, сероземов $-1,34 \%$. Соединения азота, который гидролизируется, вмещает лишь небольшую часть азота органических веществ почвы. Основная часть запасов азота представлена наиболее крепко связанными компонентами гуминов [3]. Сопоставление запасов разных форм соединений азота по типами почв обнаруживает ту же закономерность, что и по свойствам гуминовых кислот. Чем интенсивнее накапливается гумус, тем выше в почве общие запасы азота, и тем больше накапливается труднорастворимых и слабо подвижных соединений [4].

Аминокислотный состав почвы в целом и аминокислотный состав гумусовых веществ в частности совпадают по своей структуре. Большинство аминокислот входят в состав не только гумусовых веществ, но и к другим органическим веществам, кроме глицина, который входит только в состав гумусовых веществ. Эта аминокислота связывается в почве только с соединением гумуса, то есть может быть использована в качестве главного информативного параметра.

Целью статьи является разработка методики оценивания неопределенности измерений при использовании средства измерения (СИ) построенного за принципом аналого-цифрового преобразования.

Алгоритм оценивания неопределенностей составляющих элементов СИ концентрации ионов.

Уравнение преобразования ионоселективного преобразователя имеет вид [5]

$$
\Delta U=U_{0}+\frac{2,3 R T}{n_{A} F} \lg \left(a_{A}+K_{c}\left(a_{B}\right)^{n_{A} / n_{B}}\right)
$$

где $\Delta U$ - разность потенциалов на выходе преобразователя; $U_{0}$ - стандартный постоянный потенциал чувствительного элемента (электрода сравнения $\left.U_{0}=201 \pm 3 \mathrm{MB}\right) ; R-$ универсальная газовая постоянная; $T$ - абсолютная температура исследуемой концентрации; $F$ - число Фарадея; $n_{A}, n_{B}$ - заряды ионов $A$ и $B$, соответственно; $a_{A}$ - активность ионов $A$, которую нужно определить; $a_{B}$ - активность ионов $B$, которые мешают определению ионов $A ; K_{c}$-коэффициент селективности (максимально возможное значение $10^{-1}$ при определении активности ионов фторида).
Поскольку при измерении концентрации ионов гумусового состояния почв необходимо определять содержание таких одновалентных веществ как фторид, нитратный азот, аммонийный азот, калий, то в уравнении (1) отношение $\frac{2,3 R T}{n_{A} F}$ есть постоянной величиной, что отображает чувствительность ионоселективных электродов по отношению к ионам $A$, которая равняется $S=59,16 \mathrm{MB}$ при температуре калибровки $25^{\circ} \mathrm{C}$.

Изменение активности ионов приводит к изменению разности потенциалов. Для дальнейшего усиления малых разностей потенциалов в СИ используется измерительный усилитель, который должен удовлетворить следующие требования:

- дифференциальный вход для уменьшения действия синфазной помехи;

- низкий уровень нулевого сигналу;

- большой коэффициент послабления синфазной помехи.

После усиления измерительный сигнал поступает на вход аналого-цифрового преобразователя (АЦП), где превращается в двоичный код $N$.

Таким образом, учитывая составные элементы вторичного средства измерения уравнения преобразования (1) примет вид:

$$
N=\left[U_{0}+S \lg \left(a_{A}+0,1 a_{B}\right)\right] \frac{K 2^{m}}{U_{\text {оп }}},
$$

где $U_{\text {оп }}$ - опорное напряжение АЦП (5 B); $m$ - разрядность АЦП $(\mathrm{m}=16) ; K-$ коэффициент усиления измерительного усилителя.

Из данных предыдущих исследований известно, что границы не исключённых остатков систематических погрешностей такие:

- стандартного потенциала $U_{0}$ чувствительного элемента $\theta_{U 0}= \pm 3 \mathrm{MB}$;

- значения абсолютной погрешности измерения активности ионов $\theta_{a}=5 \cdot 10^{-6} \frac{\text { моль }}{\partial \mu^{3}}$;

- максимальный температурный коэффициент сдвига измерительного усилителя составляет $0,25 \mathrm{MB} /{ }^{\circ} \mathrm{C}$;

- температурный коэффициент опорного напряжения АЦП составляет $k_{t}=10^{-5} /{ }^{\circ} \mathrm{C}$;

- отклонения опорного напряжения от номинального значения не превышает $\theta_{U_{\text {оп }}}= \pm 0,02 \mathrm{~B}$. В предположении о равномерном законе распределения $[6,7]$ стандартную неопределенность потенциала чувствительного элемента, определим, как 


$$
u_{U 0}=\frac{\theta_{U 0}}{\sqrt{3}} \approx 1,73 \mathrm{MB} .
$$

Стандартную неопределенность, которая обусловлена абсолютной погрешностью измерения концентрации ионов в предположении о нормальном законе распределения погрешности внутри границ $[6,7]$ вычисляем по формуле

$$
u_{a}=\frac{\theta_{a}}{k} \approx 2,55 \cdot 10^{-3} \frac{\text { ммоль }}{\text { дм }^{3}},
$$

где $k$ - коэффициент охвата для нормального распределения, который равный 1,96 для вероятности $95 \%$ [7].

Суммарную стандартную неопределенность, которая вносится ионоселективными электродами $u_{\text {ипs }}$, вычисленную по типу $B$, с учетом уравнений (3) и (4), определим по формуле

$$
u_{\mathrm{\text {पाIs }}}^{2}=\left(\frac{\partial \Delta U}{\partial U_{0}}\right)^{2} u_{U 0}^{2}+\left(\frac{\partial \Delta U}{\partial a_{A}}\right)^{2} u_{a}^{2}+\left(\frac{\partial \Delta U}{\partial a_{B}}\right)^{2} u_{a}^{2},
$$

где $\frac{\partial \Delta U}{\partial U_{0}}=1-$ коэффициент чувствительности стандартного потенциала; $\frac{\partial \Delta U}{\partial a_{A}}=\frac{S}{2,3\left(a_{A}+K_{c} a_{B}\right)}-$ коэффициент чувствительности измеряемой активности ионов $\mathrm{A}$, который на нижнем диапазоне измерений $\left(D_{\min }=10^{-6}\right.$ моль $/$ дм $\left.^{3}\right) \quad$ равен 23383,4 Вдм ${ }^{3} /$ моль $; \quad \frac{\partial \Delta U}{\partial a_{B}}=\frac{K_{c} S}{2,3\left(a_{A}+K_{c} a_{B}\right)}-$ коэффициент чувствительности активности ионов $\mathrm{B}$, что мешают определению измеряемых ионов А, который на нижнем диапазоне измерений $\left(D_{\min }=10^{-6}\right.$ моль/ дм $\left.{ }^{3}\right)$ равен 2338,34 Вдм $^{3} /$ моль.

Подставляя рассчитанные значения коэффициентов чувствительности в уравнение (5) суммарная стандартная неопределенность, которая вносится ионоселективными электродами составит $u_{\text {иПь }} \approx 60 \mathrm{MB}$.

Поскольку измерения могут проводится при изменении температуры окружающей среды от 5 до $40{ }^{\circ} \mathrm{C}$, максимальное изменение температуры при этом составляет $\Delta t=35^{\circ} \mathrm{C}$, то учитывая температурный коэффициент сдвига усилителя $0,25 \mathrm{MB} /{ }^{\circ} \mathrm{C}$, напряжения смещения составит $\mathrm{U}_{\mathrm{cm}}=35^{\circ} \mathrm{C} \cdot 0,25 \mathrm{MB} /{ }^{\circ} \mathrm{C}=8,75 \mathrm{мB}$. При известном коэффициенте усиления $\mathrm{K}=10$, максимальное напряжение смещения будет равным $U_{\text {смmax }}=U_{\text {см }} \cdot K=87,5 \mathrm{mB}$. Учитывая максимальное выходное напряжения усилителя $U_{\text {вых }}= \pm 5 \mathrm{~B}$, его максимальную относительную погрешность можно рассчитать по формуле

$$
\delta_{K}=\frac{\mathrm{U}_{\text {смmax }}}{2 \mathrm{U}_{\text {вых }}}=8,75 \cdot 10^{-3} .
$$

Рассчитав максимальную относительную погрешность усилителя, стандартную неопределенность, которая вносится усилителем при измерении концентрации ионов в предположении о нормальном законе распределения, рассчитаем по формуле:

$$
u_{K}=\frac{\Delta U_{\max } \delta_{K}}{k} \approx 0,83 \mathrm{MB},
$$

где $\Delta U_{\max }$ - максимальная разность потенциалов, которая соответствует максимальной активности ионов нитратного азота (максимальный диапазон измерения $D_{\max }=0,5$ моль $/$ дм $^{3}$ ) при максимально возможной активности мешающих ионов $B$.

Неопределенность $u_{\mathrm{O \Pi}}(\Delta t)$, обусловленная изменениям опорного напряжения источника при изменении температуры окружающей среды от $25^{\circ} \mathrm{C}$ (температура калибровки источника опорного напряжения АЦП $t_{1}$ ) до $35^{\circ} \mathrm{C}$ (максимально возможное изменения температуры окружающей среды $\Delta t$ ), вычисленная через температурный коэффициент, в предположении о равномерном распределении границ, будет равной

$$
u_{\text {ОП }}(\Delta \mathrm{t})=\frac{k_{t}\left(\Delta t-t_{1}\right)}{\sqrt{3}} U_{\text {оп }} \approx 0,43 \mathrm{мB} .
$$

Неопределенность $u_{\text {ОП }}(\theta)$, обусловленная отклонения опорного напряжения от номинального значения, в предположении о равномерном распределении, будет равной

$$
u_{U 0}=\frac{\theta_{U_{\text {оП }}}}{\sqrt{3}} \approx 11,55 \mathrm{MB} .
$$

Таким образом, суммарная стандартная неопределенность источника опорного напряжения АЦП, которая состоит из неопределенностей рассчитанных по формулам (8) и (9), будет равной

$$
u_{\text {ОП }}=\sqrt{\left(u_{\text {оП }}(\mathrm{t})\right)^{2}+\left(u_{U 0}\right)^{2}} \approx 11,56 \mathrm{MB} .
$$

Стандартную неопределенность $\mathrm{u}_{\mathrm{h}}$, которая вносится процессом квантования напряжения, что поступает на вход АЦП, в предположении о равномерном законе распределения, определим так

$$
u_{h}=\frac{h}{\sqrt{3}}=\frac{U_{\mathrm{O \Pi}}}{2^{m} \sqrt{3}} \approx 44,05 \mathrm{м \kappa B} .
$$

Учитывая рассчитанные по формулам (5), (7), (10) и (11) стандартные неопределенности, на каждом из этапов преобразования, суммарную стандартную неопределенность типа В вычислим по формуле 


$$
u_{S}=\sqrt{u_{\text {ИП }}^{2}+u_{K}^{2}+u_{\text {оП }}^{2}+u_{h}^{2}} \approx 61,11 \mathrm{MB} .
$$

Таким образом, анализируя полученные результаты видно, что максимальная неопределенность 60 мВ вносится первичным ионоселективным преобразователем, а суммарной неопределенности типа $B$ не превышает $61,11 \mathrm{mB}$.

\section{Выводы}

На основании справочных данных и данных предыдущих исследований, предложено методику оценивания неопределенности, вносимой СИ концентрации ионов, которая в диапазоне измерения от $10^{-6}$ до $5 \cdot 10^{-1}$ моль/дм ${ }^{3}$ составляет 61,11 мВ при максимальной активности мешающих ионов.

\section{Список использованных источников}

1. Обухов А.И. Атомно-абсорбционный анализ в почвенно-биологических исследованиях /А. И. Обухов, И. О. Плеханов. - М.: МГУ, 1991. $-254 \mathrm{c}$.

2. Замана С.П. Определение водорастворимого органического вещества почвы с помощью потенциометрического титрования / С. П. Замана // Химия в сельском хозяйстве. 1993. - № 5/6. - С. $16-21$.
3. Орлов Д. С. Гумусовые кислоты почв и общая теория гумификации / Д.С. Орлов. - М.: Из-во МГУ, 1990. - 322 с.

4. Багаутдинов Ф. Я. Аминокислотный состав гумусовых веществ и новообразованных гуминовых кислот некоторых типов целинных и пахотных почв / Ф.Я. Багаутдинов // Агрохимия. - 1992. - № 11. - С. 89 - 97.

5. Васілевський О. М. Елементи теорії побудови потенціометричних засобів вимірювального контролю активності іонів 3 підвищеною вірогідністю : [монографія] / О.М. Васілевський, В.М. Дідич. - Вінниця: ВНТУ. - 2013. - 176 с.

6. Васілевський О. М. Алгоритм оцінювання невизначеності у вимірюваннях при виконанні метрологічних робіт / О.М. Васілевський // Інформаційні технології та комп'ютерна інженерія. - 2006. - № 3 (7). - С. 147 - 151.

7. Васілевський О.М. Основи теорії невизначеності вимірювань : [підручник] / О. М. Васілевський, В. Ю. Кучерук, С. Т. Володарський. - Вінниця: ВНТУ, 2015. - 229 с. ISBN 978-966-641-632-5.

Надійила до редакиії 20.10.2015

Рецензент: д.т.н., проф. Кучерук В. Ю., Вінницький національний технічний університет, м. Вінниця.

О. М. Васілевський, д.Т.Н., О. Д. Никитенко, к.т.н.

\section{ДОСЛІДЖЕННЯ НЕВИЗНАЧЕНОСТІ ВИМІРЮВАННЯ КОНЦЕНТРАЦІЇ ІОНІВ ПРИ ВИКОРИСТАННІ ЗАСОБУ ВИМІРЮВАННЯ ПОБУДОВАНОГО ЗА ПРИНЦИПОМ АНАЛОГО-ЦИФРОВОГО ПРЕТВОРЕННЯ}

Виконано очінювання точності вимірювання концентрачії іонів з урахуванням міжнародних вимог щуодо подання якості результатів вимірювань. Встановлено значення сумарної невизначеності типу $B$, шо обумовлене обмеженими властивостями складових елементів засобу вимірювання концентрачії іонів.

Ключові слова: рівняння перетворення, концентрачія іонів, стандартна невизначеність, засіб вимірювання, іон-селективний перетворювач.

O. M. Vasilevskyi, DSc, O. D. Nykytenko, $\mathrm{PhD}$

\section{RESEARCH OF MEASUREMENT UNCERTAINTY OF ION CONCENTRATION WHEN USING THE MEASURING MEANS OF BUILT ON PRINCIPLE THE ANALOG-DIGITAL CONVERSION}

Carried out evaluation of the accuracy of measuring the concentration of ions in accordance with international requirements for submission quality results. It is set to the overall uncertainty of type $B$, which is due to the limited properties of the constituent elements of the ion concentration measuring means.

Keywords: transformation equation, the concentration of ions, the standard uncertainty, measuring instruments, ion-selective converter. 